\title{
Radio-frequency ablation-based studies on VX2rabbit models for HCC treatment
}

\author{
Sabrina Bimonte ${ }^{1 * \dagger}$, Maddalena Leongito $^{1 \dagger}$, Mauro Piccirillo $^{1}$, Cristina de Angelis $^{2}$, Claudia Pivonello $^{3}$, \\ Vincenza Granata ${ }^{1}$ and Francesco Izzo ${ }^{1}$
}

\begin{abstract}
Hepatocellular carcinoma (HCC) is the fifth most frequent cancer worldwide with high morbidity, mortality and increasing incidence. It is of note that the main curative therapies for HCC are hepatic resection and transplantation although the majority of patients at the time of presentation are not eligible for resection or orthotopic liver transplantation (OLT) due to the underlying cirrhosis. Currently, a variety of loco-regional therapies, including radiofrequency ablation (RFA), percutaneous ethanol injection (PEI), microwave coagulation therapy (MCT), transarterial chemoembolization (TACE) and others, have been developed as alternative treatment options for HCC. Among these techniques, RFA is currently the most widely used treatment, due to its several advantages, such as safety and efficacy. To date, the effectiveness of RFA for HCC is reduced by the presence of residual tumor as a consequence of insufficient treatment. In order to ameliorate the effects of RFA on HCC, several in vivo studies, have been performed on its application as single or in combination treatment with drugs or others loco-regional therapies, by using rabbit VX2 liver model. This represents an ideal model of liver cancers and is widely used for imaging and other experimental studies due to the rapid growth of these tumors and their similarity to human hepatocellular carcinoma. In order to elucidate the therapeutic potential of RFA with adjuvant treatments for HCC, we reviewed the latest findings on the RFA-based studies in rabbit VX2 hepatocarcinoma models.
\end{abstract}

Keywords: Hepatocellular carcinoma, RFA, Radiofrequency ablation, V×2 tumors, Residual tumor

\section{Background}

HCC is still one of the most important diseases for health care systems due to its high mortality, morbidity, and increasing incidence worldwide $[1,2]$. It is of note that the main curative therapies for HCC are hepatic resection and transplantation although the majority of patients at the time of presentation are not eligible for resection or OLT due to the underlying cirrhosis. Difficulties in surgical resection may be associated to site, size, and number of tumors, vascular and extra hepatic involvement as well as the general condition and liver function of the patients [3-6]. Only about $20 \%$ of HCC cases are classified as resectable [7]. Moreover, the liver is considered a site of metastasis from other solid cancers [8-12]. To date, a variety of locoregional therapies, RFA, PEI, MCT, TACE and others, have

\footnotetext{
* Correspondence: s.bimonte@istitutotumori.na.it

${ }^{\dagger}$ Equal contributors

'Division of Abdominal Surgical Oncology, Hepatobiliary Unit, Istituto

Nazionale per lo studio e la cura dei Tumori "Fondazione G. Pascale", - IRCCS, Via Mariano Semmola, 80131 Naples, Italy

Full list of author information is available at the end of the article
}

been developed as alternative treatment options for HCC due to its benefits, such as safety, minimal invasiveness, and efficacy [7]. It has been demonstrated that the effectiveness of RFA for HCC was reduced by the presence of residual tumor and local recurrence after treatment, probably due to the location of tumor around the intrahepatic vasculature [13] or to the diameter of tumor. Several studies showed that, residual tumor progression after insufficient RFA could be associated to different reasons and molecular mechanisms [14-18] in particular to the inflammation process which is involved in tumor progression of different types of cancer $[19,20]$. The inflammation is induced by thermal destruction of liver carcinoma after RFA at the target sites, leading to progression of HCC tumor [20].

In order to ameliorate the effects of RFA on HCC and to bypass the problem of residual tumor, several in vivo studies have been performed on its application as single or in combination treatment with drugs or other locoregional therapies, by using rabbit VX2 liver carcinoma model [18, 21-24]. 
The rabbit VX2 tumor model is widely used in experimental oncology. It is classified as leporine anaplastic squamous cell carcinoma being characterized by rapid growth, hypervascularity and easy propagation in the skeletal muscle [25-28]. This model has been applied to various types of cancer [29-38], and recently it has been used in doxorubicin interventional chemotherapy of renal carcinoma [39]. The transplantation of the VX2 cells can be achieved either by injecting the tumor cell suspensions or by implanting solid tumor pieces (fresh o frozen) as previously described [40].

This represents an ideal model of liver cancers due to the rapid growth of VX2 tumors and their similarity to human hepatocellular carcinoma. Here we reviewed the latest findings on the RFA based studies in rabbit VX2 hepatocarcinoma models, with the aim of elucidating the therapeutic potential of RFA with adjuvant treatments for HCC.

\section{Generation of VX2 model for liver tumor treatment: an overview of loco regional therapy-based studies}

Several studies demonstrated that intrahepatic implantation of solid tumor fragments is more successfully that the injection of a cell suspension [41-43], although a sonography implantation of liver tumors achieved a good success rate [44]. The protocol for liver implantation has been detailed described by Parvivian et al. [40]. It is of note that the preferred implantation site for VX2 tumors is the left lateral hepatic lobe due to a more favorable angle of the feeding artery for later angiographic catheterization. Our group and other researchers demonstrated that the tumors developed after 2-4 weeks form tissue implantation with nodules of 2-3 cm [38] (Fig. 1).

It also has been reported that the application of ultrasonography, is useful to following the solid tumor growth and to detect the presence of necrosis [44]. The use of non-necrotic tumors allows optimizing the evaluation of tumor response to loco-regional therapy experiments. It is largely provided that loco-regional therapies, including RFA and TACE, play a major role in the clinical management of hepatocellular carcinoma [45]. Regarding pre-clinical studies, many evidences reported the safety and the efficacy of different loco-regional treatments in rabbit VX2 liver tumor model, especially in combination with adjuvant substances. Gholamrezanezhad et al., evaluated the pharmacokinetic profile (PK) and embolization effect of $70-150-\mu \mathrm{m}$ doxorubicin eluting beads (DEBs) following intra-arterial injection, in the rabbit liver VX2 tumor model [46]. In VX2 model of liver metastases, it has been reported that HepaSphere and DEBS microspheres loaded with irinotecan, caused significant necrosis of tumor nodules [47]. Xia et al,, showed that intra-arterial interleukin-12 gene delivery combined with chemoembolization, had a potent anti-tumor effect in a VX2 rabbit HCC [48]. In another study performed on the rabbit VX2 liver tumor model, was demonstrated that the application of Electroporation-Mediated Transcatheter Arterial Chemoembolization (E-TACE) increased liver tumor chemotherapeutic uptake following targeted transcatheter infusion [49]. In addition, Deng et al., showed that TACE with arterial administration of Endostar (an antiangiogenic agent) inhibited the angiogenesis biomarkers associated with TACE in a rabbit model bearing VX2 liver tumor [50]. Potentiated anti-tumor effects on liver cancer, were also observed in a similar study with chloroquine and TACE. The authors showed that chloroquine, which is a traditional drug used for treatment of malaria [51], promoted the anticancer effect of TACE in a rabbit VX2 liver tumor model. Other studies proved that single-bolus regional chemotherapy with doxorubicin, had limited anti-tumor effects when compared with TACE in a rabbit VX2 liver tumor model [52]. Very recently, it has been reported that the elaborate integration of TACE with nanoparticle-enhanced High-intensity focused ultrasound (HIFU) cancer surgery, applied in VX2 liver tumor model, could efficiently enhance the HCC cancer treatment outcome, representing a new and efficient therapeutic proto$\mathrm{col} /$ modality for clinic cancer treatment [53]. Another research demonstrated that Transarterial oily chemoembolization (TOCE), one of the most effective approaches for
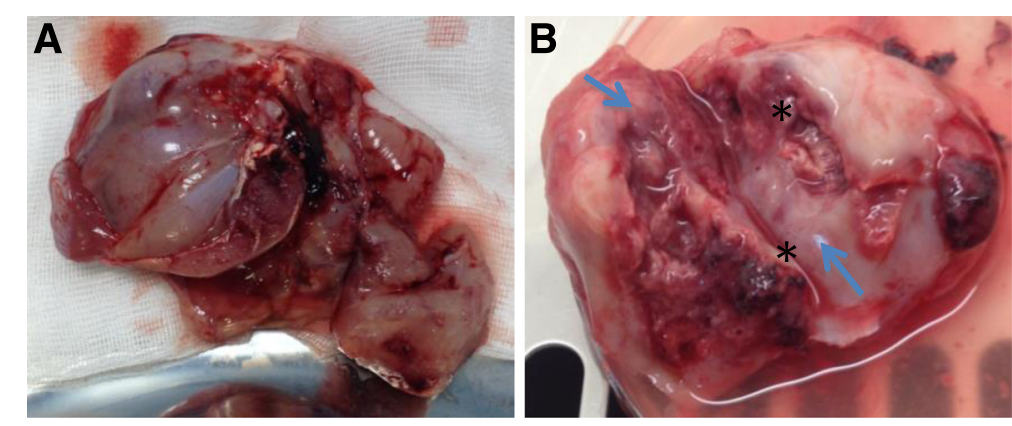

Fig. 1 VX2 tumor liver development. a Picture reveals resected hepatic tumor after 4 week from VX2 tumor pieces implant, b Tumor bisected shows necrotic core (asterisk) and peripheral viable tumor (arrows) 
the treatment of patients with $\mathrm{HCC}$, who are not suitable for surgical therapy [54], combined with Lidamycin (LDM) [55], shows potent therapeutic efficacy in VX2 rabbit liver tumor model. Synergistic effects of RFA and toll like receptor 9 (TRL9) stimulation result in a potentiated antitumor $\mathrm{T}$ cell response and cytotoxicity in the VX2 hepatoma tumor [23].

Taken together all these different data, summarized in Table 1, suggest that these combined treatments may have potential synergistic effects on liver cancer.

\section{Radio-frequency ablation of VX2 rabbits model for HCC treatment: experimental studies}

RFA is considered one of the standard procedures for local tumor treatment such as prostate [56, 57], kidney [56], bone [58, 59], brain $[60,61]$, lung $[62,63]$ and liver tumors $[45,64-67]$. RFA is commonly used for the treatment of early HCC, although recently the technique has been improved to bypass the problem of burden for patients and operators [68]. RFA is classified as thermal technique since induces cell tumor destruction by heating tumor tissue to high temperatures $[69,70]$. It is important to underline that the effectiveness of RFA for HCC is reduced by the presence of residual tumor as a consequence of insufficient treatment. It is very difficult to avoid the residual tumor due to several causes such as the liver's anatomy, the mechanisms of RFA, the pathological characteristics of HCC and the inflammation. It has been demonstrated that despite it is possible to set the target temperature around $105-115{ }^{\circ} \mathrm{C}$ during RFA, only the tissues surrounding the electrodes can reach that temperature due to "heat sink" effect of blood large vessels near the tumor [71].

Table 1 Effects of Loco-regional treatments on tumor growth in VX2 rabbit model of liver cancer

\begin{tabular}{llll}
\hline Animal model & Treatment & Effects on tumor & Reference \\
\hline $\begin{array}{l}\text { Rabbit Vx2 liver } \\
\text { tumor model }\end{array}$ & TACE, DEBs & $\begin{array}{l}\text { Tumor growth } \\
\text { reduction }\end{array}$ & {$[46]$} \\
$\begin{array}{l}\text { Rabbit VX2 liver } \\
\text { metastis model }\end{array}$ & $\begin{array}{l}\text { HepaSphere and DC } \\
\text { Bead microspheres } \\
\text { loaded with }\end{array}$ & $\begin{array}{l}\text { Enhanced Tumor } \\
\text { necrosis }\end{array}$ & {$[47]$} \\
Rabbit VX2 & IL12, TACE & $\begin{array}{l}\text { Tumor growth } \\
\text { reduction }\end{array}$ & {$[48]$} \\
HCC model & Endostar, TACE & $\begin{array}{l}\text { Tumor growth } \\
\text { reduction }\end{array}$ & {$[50]$} \\
$\begin{array}{l}\text { Rabbit VX2 } \\
\text { HCC model }\end{array}$ & $\begin{array}{l}\text { Tumor growth } \\
\text { reduction }\end{array}$ & {$[51]$} \\
$\begin{array}{l}\text { Rabbit VX2 } \\
\text { liver model }\end{array}$ & Chloroquine, TACE & \\
$\begin{array}{l}\text { Rabbit VX2 } \\
\text { liver model }\end{array}$ & TACE, HIFU & $\begin{array}{l}\text { Tumor growth } \\
\text { reduction }\end{array}$ & {$[53]$} \\
$\begin{array}{l}\text { Rabbit VX2 liver } \\
\text { tumor model }\end{array}$ & LDM, TOCE & $\begin{array}{l}\text { Tumor growth } \\
\text { reduction }\end{array}$ & {$[54]$} \\
$\begin{array}{l}\text { Rabbit VX2 } \\
\text { HCC model }\end{array}$ & TRL9, RFA & $\begin{array}{l}\text { Tumor growth } \\
\text { reduction }\end{array}$ & {$[23]$} \\
\hline
\end{tabular}

Abbreviations: TACE transcatheter arterial chemoembolization, IL-12 interleukin-12, LDM Lidamycin, TOCE transarterial oily chemoembolization, HIFU high-intensity focused ultrasound, TRL9 toll like receptor 9
Table 2 Effects of RFA on the progression of residual HCC in VX2 rabbit model of liver cancer

\begin{tabular}{llll}
\hline Animal model & Treatment & $\begin{array}{l}\text { Effects on the progression } \\
\text { of residual HCC }\end{array}$ & References \\
\hline $\begin{array}{llll}\text { Rabbit VX2 } \\
\text { HCC model }\end{array}$ & $\begin{array}{l}\text { RFA at different } \\
\text { temperatures } \\
\left(55,70 \text { and } 85^{\circ} \mathrm{C}\right)\end{array}$ & $\begin{array}{l}\text { Low temperatures } \\
\text { induce rapid progression } \\
\text { of residual HCC. } \\
\text { Tumor progression } \\
\text { is associated to PCNA, } \\
\text { MMP-9, and VEGF, HGF } \\
\text { and IL-6 overexpression. }\end{array}$ \\
Rabbit VX2 & Aspirin, RFA & $\begin{array}{l}\text { Reduced progression of } \\
\text { residual HCC associated } \\
\text { to reduced inflammation. }\end{array}$ \\
\hline HCC model & &
\end{tabular}

Many evidences have demonstrated a rapid progression of residual HCC after RFA [72, 73]. In addition, this tumor becoming very aggressive, switches to sarcoma $[74,75]$ thus leading to bad prognosis for patients.

In order to ameliorate the effects of RFA on HCC and to clarify the underlying mechanisms of rapid progression of residual tumor after insufficient RFA, several in vivo studies, have been performed using rabbit VX2 hepatocarcinoma model. The study conducted by Ke et al., was designed to prove whether low temperature of RFA at the target sites, and could facilitate progression of residual hepatic VX2 carcinoma trying to dissect the underlying mechanisms. The VX2 nodules were transplanted into the liver rather than derived from the liver itself, in order to reduce the feeding artery and the heat sink effect. The residual VX2 hepatoma model in rabbits was established by using RFA at different temperatures $\left(55,70\right.$ and $\left.85{ }^{\circ} \mathrm{C}\right)$. Actually, it is of note that different molecular factors are involved in HCC progression and metastasis, such as IL-6, PCNA, MMP-9, VEGF, HGF [76-78]. The authors demonstrated that residual hepatic VX2carcinoma facilitated its progression through inducing over expression of several molecular factors, such as PCNA, MMP-9, VEGF, HGF and IL-6 [18].

In another research, was proved that the inflammation induced by RFA at the target sites, facilitated the progression of residual HCC tumor [21]. The authors generated the orthotropic VX2 rabbit HCC model with two hepatic tumors in different lobes and treated the animals with different doses of aspirin used as anti-inflammatory drug. Results from this study demonstrated that aspirin inhibited the inflammatory reaction of animals after RFA, suggesting that aspirin could be potentially used as an adjuvant therapy with RFA for treating HCC. Table 2 summirizes the effects of RFA on the progression of residual HCC in VX2 rabbit model of liver cancer.

\section{Conclusions}

Altogether these data suggest that inflammation and low temperature of RFA at the target sites could be important reasons for rapid progression of residual hepatic VX2 
carcinoma. Future studies will be needed to validate the therapeutic potential of drugs or other loco-regional techniques as an adjuvant therapy with RFA for treating HCC.

\begin{abstract}
Abbreviations
(E-TACE), Electroporation-Mediated Transcatheter Arterial Chemoembolization; (HIFU), high-intensity focused ultrasound; DEBs, doxorubicin eluting beads; HCC, hepatocellular carcinoma; HGF, hepatocyte growth factor; IL-6, Interleukin-6; LDM, lidamycin; $\mathrm{MCT}$, microwave coagulation therapy; MDR, multidrug resistance; MMP-9, matrix metallopeptidase 9; OLT, orthotopic liver transplantation; PCNA, Proliferating cell nuclear antigen; PEl, percutaneous ethanol injection; PK, pharmacokinetic profile; RFA, radiofrequency ablation; TACE, transcatheter arterial chemoembolization; TOCE, transarterial oily chemoembolization; TRL9, toll like receptor 9; VEGF, Vascular endothelial growth factor
\end{abstract}

\section{Acknowledgements}

This work was supported by current research programs of National Institute of Tumors, IRCCS Fondazione G. Pascale, Italy and I.O.S \& Coleman Srl, Naples, Italy.

\section{Authors' contributions}

The manuscript was written by SB and ML. MP, VG, Cd, CV performed bibliographic research. FI and SB revised the manuscript. All authors read and approved the final manuscript.

\section{Competing interests}

The authors declare that they have no competing interests.

\section{Ethical approval}

Not applicable.

\section{Author details}

'Division of Abdominal Surgical Oncology, Hepatobiliary Unit, Istituto Nazionale per lo studio e la cura dei Tumori "Fondazione G. Pascale", - IRCCS, Via Mariano Semmola, 80131 Naples, Italy. ${ }^{2}$ I.O.S. \& Coleman Srl, Naples, Italy. ${ }^{3}$ Dipartimento di Medicina Clinica e Chirurgia, Sezione di Endocrinologia, Università di Napoli Federico II, Naples, Italy.

\section{Received: 29 April 2016 Accepted: 30 May 2016}

\section{Published online: 12 August 2016}

\section{References}

1. El-Serag HB. Hepatocellular carcinoma. N Engl J Med. 2011;365(12):1118-27.

2. Shariff MI, Cox IJ, Gomaa Al, Khan SA, Gedroyc W, Taylor-Robinson SD. Hepatocellular carcinoma: current trends in worldwide epidemiology, risk factors, diagnosis and therapeutics. Expert Rev Gastroenterol Hepatol. 2009;3(4):353-67.

3. Cho YK, Kim JK, Kim WT, Chung JW. Hepatic resection versus radiofrequency ablation for very early stage hepatocellular carcinoma: a Markov model analysis. Hepatology. 2010;51(4):1284-90.

4. Rust C, Gores GJ. Locoregional management of hepatocellular carcinoma. Surgical and ablation therapies. Clin Liver Dis. 2001;5(1):161-73.

5. Lee WS, Yun SH, Chun HK, Lee WY, Kim SJ, Choi SH, et al. Clinical outcomes of hepatic resection and radiofrequency ablation in patients with solitary colorectal liver metastasis. J Clin Gastroenterol. 2008;42(8):945-9.

6. Mulier S, Ruers T, Jamart J, Michel L, Marchal G, Ni Y. Radiofrequency ablation versus resection for resectable colorectal liver metastases: time for a randomized trial? An update. Dig Surg. 2008;25(6):445-60

7. Lau WY, Lai EC. The current role of radiofrequency ablation in the management of hepatocellular carcinoma: a systematic review. Ann Surg. 2009;249(1):20-5.

8. Zavadsky KE, Lee YT. Liver metastases from colorectal carcinoma: incidence, resectability, and survival results. Am Surg. 1994;60(12):929-33.

9. McCaughan GW, Koorey DJ, Strasser SI. Hepatocellular carcinoma: current approaches to diagnosis and management. Intern Med J. 2002;32(8):394-400.

10. Liu LX, Zhang WH, Jiang HC. Current treatment for liver metastases from colorectal cancer. World J Gastroenterol. 2003;9(2):193-200.

11. Tsim NC, Frampton AE, Habib NA, Jiao LR. Surgical treatment for liver cancer. World J Gastroenterol. 2010;16(8):927-33.

12. Michalski CW, Erkan M, Huser N, Muller MW, Hartel M, Friess $H$, et al. Resection of primary pancreatic cancer and liver metastasis: a systematic review. Dig Surg. 2008;25(6):473-80.
13. Chen X, Liu HP, Li M, Qiao L. Advances in non-surgical management of primary liver cancer. World I Gastroenterol. 2014;20(44):16630-8.

14. Kong J, Kong L, Kong J, Ke S, Gao J, Ding X, et al. After insufficient radiofrequency ablation, tumor-associated endothelial cells exhibit enhanced angiogenesis and promote invasiveness of residual hepatocellular carcinoma. J Transl Med. 2012;10:230.

15. Kong J, Kong J, Pan B, Ke S, Dong S, Li X, et al. Insufficient radiofrequency ablation promotes angiogenesis of residual hepatocellular carcinoma via HIF-1alpha/NEGFA. PLoS One. 2012;7(5):e37266.

16. Dong S, Kong J, Kong F, Kong J, Gao J, Ke S, et al. Insufficient radiofrequency ablation promotes epithelial-mesenchymal transition of hepatocellular carcinoma cells through Akt and ERK signaling pathways. J Transl Med. 2013;11:273.

17. Zhang N, Wang L, Chai ZT, Zhu ZM, Zhu XD, Ma DN, et al. Incomplete radiofrequency ablation enhances invasiveness and metastasis of residual cancer of hepatocellular carcinoma cell HCCLM3 via activating beta-catenin signaling. PLoS One. 2014;9(12):e115949.

18. Ke S, Ding XM, Kong J, Gao J, Wang SH, Cheng Y, et al. Low temperature of radiofrequency ablation at the target sites can facilitate rapid progression of residual hepatic VX2 carcinoma. J Transl Med. 2010;8:73.

19. Wu Y, Zhou BP. Inflammation: a driving force speeds cancer metastasis. Cell Cycle. 2009;8(20):3267-73.

20. Schleimer RP. Inflammation: Basic principles and clinical correlates edited by John Gallin, Ira Goldstein and Ralph Snyderman, Raven Press, 1987. \$219.00 (xvii + 995 pages) ISBN 088167344 7. Immunol Today. 1988;9(10):327.

21. Jiang T, Zhang X, Ding J, Duan B, Lu S. Inflammation and cancer: inhibiting the progression of residual hepatic VX2 carcinoma by anti-inflammatory drug after incomplete radiofrequency ablation. Int I Clin Exp Pathol. 2015; 8(11):13945-56.

22. Weinberg BD, Blanco E, Lempka SF, Anderson JM, Exner AA, Gao J. Combined radiofrequency ablation and doxorubicin-eluting polymer implants for liver cancer treatment. J Biomed Mater Res A. 2007;81(1):205-13.

23. Behm B, Di Fazio P, Michl P, Neureiter D, Kemmerling R, Hahn EG, et al. Additive antitumour response to the rabbit VX2 hepatoma by combined radio frequency ablation and toll like receptor 9 stimulation. Gut. 2016;65(1):134-43.

24. Fan $L$, He Z, Ma K, Huang $X$, Zhou D, Feng $X$, et al. Hepatic VX2 tumor in rabbits: treated with radio frequency ablation and evaluated with enhanced CT. Zhonghua Gan Zang Bing Za Zhi. 2002;10(5):362-5.

25. Rous P, Beard JW. The progression to carcinoma of virus-induced rabbit papillomas (Shope). J Exp Med. 1935;62(4):523-48.

26. Kidd JG, Rous P. A transplantable rabbit carcinoma originating in a virusinduced papilloma and containing the virus in masked or altered form. J Exp Med. 1940;71(6):813-38.

27. Galasko CS, Muckle DS. Intrasarcolemmal proliferation of the VX2 carcinoma. Br J Cancer. 1974;29(1):59-65.

28. Maruyama H, Matsutani $\mathrm{S}$, Saisho H, Kamiyama N, Mine $\mathrm{Y}$, Hirata T, et al. Sonographic shift of hypervascular liver tumor on blood pool harmonic images with definity: time-related changes of contrast-enhanced appearance in rabbit VX2 tumor under extra-low acoustic power. Eur J Radiol. 2005;56(1):60-5.

29. van Es RJ, Dullens HF, van der Bilt A, Koole R, Slootweg PJ. Evaluation of the VX2 rabbit auricle carcinoma as a model for head and neck cancer in humans. J Craniomaxillofac Surg. 2000;28(5):300-7.

30. Lee JM, Kim SW, Chung GH, Lee SY, Han YM, Kim CS. Open radio-frequency thermal ablation of renal VX2 tumors in a rabbit model using a cooled-tip electrode: feasibility, safety, and effectiveness. Eur Radiol. 2003;13(6):1324-32.

31. Frank JA, Girton M, Dwyer AJ, Cohen PJ, Knop RH, Diggs R, et al. A reproducible model of metastatic brain and ocular tumor by hematogenous inoculation of the VX2 tumor in rabbits. J Neurosurg. 1987;67(1):106-9.

32. Anayama T, Nakajima T, Dunne M, Zheng J, Allen C, Driscoll B, et al. A novel minimally invasive technique to create a rabbit VX2 lung tumor model for nano-sized image contrast and interventional studies. PLoS One. 2013;8(6):e67355.

33. Yang WH, Liebert M, Price RE, Cromeens DM, Lin JS, Grossman HB. Extravesical cryosurgical approach for VX2 bladder tumor in rabbits. Urol Res. 2001;29(5):345-9.

34. Rhee TK, Young JY, Larson AC, Haines 3rd GK, Sato KT, Salem R, et al. Effect of transcatheter arterial embolization on levels of hypoxia-inducible factor1alpha in rabbit VX2 liver tumors. J Vasc Interv Radiol. 2007;18(5):639-45.

35. Burgener FA. Peripheral hepatic artery embolization in rabbits with VX2 carcinomas of the liver. Cancer. 1980;46(1):56-63. 
36. Hoye RC, Thomas LB, Riggle GC, Ketcham A. Effects of neodymium laser on normal liver and $V \times 2$ carcinoma transplanted into the liver of experimental animals. J Natl Cancer Inst. 1968;41(5):1071-82.

37. Eifler AC, Lewandowski RJ, Virmani S, Chung JC, Wang D, Tang RL, et al. Development of a VX2 pancreatic cancer model in rabbits: a pilot study. J Vasc Interv Radiol. 2009:20(8):1075-82.

38. Wang D, Bangash AK, Rhee TK, Woloschak GE, Paunesku T, Salem R, et al. Liver tumors: monitoring embolization in rabbits with VX2 tumors-transcatheter intraarterial first-pass perfusion MR imaging. Radiology. 2007;245(1):130-9.

39. Zhao $\mathrm{S}, \mathrm{Yu}$ H, Du N. Experimental study of doxorubicin interventional chemotherapy in the treatment of rabbit VX2 renal transplantation carcinoma. Int J Clin Exp Med. 2015;8(7):10739-45.

40. Parvinian A, Casadaban LC, Gaba RC. Development, growth, propagation, and angiographic utilization of the rabbit VX2 model of liver cancer: a pictorial primer and "how to" guide. Diagn Interv Radiol. 2014;20(4):335-40.

41. Virmani S, Harris KR, Szolc-Kowalska B, Paunesku T, Woloschak GE, Lee FT, et al. Comparison of two different methods for inoculating VX2 tumors in rabbit livers and hind limbs. J Vasc Interv Radiol. 2008;19(6):931-6.

42. Chen JH, Lin YC, Huang YS, Chen TJ, Lin WY, Han KW. Induction of VX2 carcinoma in rabbit liver: comparison of two inoculation methods. Lab Anim. 2004;38(1):79-84.

43. Sun JH, Zhang YL, Nie CH, Yu XB, Xie HY, Zhou L, et al. Considerations for two inoculation methods of rabbit hepatic tumors: Pathology and image features. Exp Ther Med. 2012;3(3):386-90.

44. Luo W, Zhou X, Zheng X, He G, Yu M, Li Q, et al. Role of sonography for implantation and sequential evaluation of a VX2 rabbit liver tumor model. J Ultrasound Med. 2010;29(1):51-60.

45. Bimonte S, Barbieri A, Palaia R, Leongito M, Albino V, Piccirillo M, et al. An overview of loco-regional treatments in patients and mouse models for hepatocellular carcinoma. Infect Agent Cancer. 2015;10:9.

46. Gholamrezanezhad A, Mirpour S, Geschwind JH, Rao P, Loffroy R, Pellerin O, et al. Evaluation of 70-150-mum doxorubicin-eluting beads for transcatheter arterial chemoembolization in the rabbit liver VX2 tumour model. Eur Radiol. 2016 [Epub ahead of print].

47. Namur J, Pascale F, Maeda N, Sterba M, Ghegediban SH, Verret V, et al. Safety and efficacy compared between irinotecan-loaded microspheres HepaSphere and DC bead in a model of VX2 liver metastases in the rabbit. J Vasc Interv Radiol. 2015;26(7):1067-75. e3.

48. Xia X, Li X, Feng G, Zheng C, Liang H, Zhou G. Intra-arterial interleukin-12 gene delivery combined with chemoembolization: anti-tumor effect in a rabbit hepatocellular carcinoma (HCC) model. Acta Radiol. 2013;54(6):684-9.

49. Guo Y, Zhang Y, Jin N, Klein R, Nicolai J, Lewandowski RJ, et al. Electroporation-mediated transcatheter arterial chemoembolization in the rabbit VX2 liver tumor model. Invest Radiol. 2012;47(2):116-20.

50. Deng G, Zhao DL, Li GC, Yu H, Teng GJ. Combination therapy of transcatheter arterial chemoembolization and arterial administration of antiangiogenesis on VX2 liver tumor. Cardiovasc Intervent Radiol. 2011;34(4):824-32.

51. Carew JS, Medina EC, Esquivel 2nd JA, Mahalingam D, Swords R, Kelly K, et al. Autophagy inhibition enhances vorinostat-induced apoptosis via ubiquitinated protein accumulation. J Cell Mol Med. 2010;14(10):2448-59.

52. Cho SK, Shin SW, Do YS, Jang KT, Choo SW, Park KB, et al. Single-bolus regional chemotherapy with doxorubicin versus chemoembolization in a rabbit VX2 tumor model. Diagn Interv Radiol. 2011;17(4):374-80.

53. You Y, Wang Z, Ran H, Zheng Y, Wang D, Xu J, et al. Nanoparticle-enhanced synergistic HIFU ablation and transarterial chemoembolization for efficient cancer therapy. Nanoscale. 2016;8(7):4324-39.

54. Marelli L, Stigliano R, Triantos C, Senzolo M, Cholongitas E, Davies N, et al. Treatment outcomes for hepatocellular carcinoma using chemoembolization in combination with other therapies. Cancer Treat Rev. 2006;32(8):594-606.

55. Shao RG, Zhen YS. Enediyne anticancer antibiotic lidamycin: chemistry, biology and pharmacology. Anticancer Agents Med Chem. 2008;8(2):123-31.

56. Zlotta AR, Wildschutz T, Raviv G, Peny MO, van Gansbeke D, Noel JC, et al. Radiofrequency interstitial tumor ablation (RITA) is a possible new modality for treatment of renal cancer: ex vivo and in vivo experience. J Endourol. 1997:11(4):251-8.

57. Mostafid AH, Harrison NW, Thomas PJ, Fletcher MS. A prospective randomized trial of interstitial radiofrequency therapy versus transurethral resection for the treatment of benign prostatic hyperplasia. Br J Urol. 1997;80(1):116-22.
58. Rosenthal DI, Alexander A, Rosenberg AE, Springfield D. Ablation of osteoid osteomas with a percutaneously placed electrode: a new procedure. Radiology. 1992;183(1):29-33.

59. Rosenthal DI, Springfield DS, Gebhardt MC, Rosenberg AE, Mankin HJ. Osteoid osteoma: percutaneous radio-frequency ablation. Radiology. 1995;197(2):451-4.

60. Cosman ER, Nashold BS, Bedenbaugh P. Stereotactic radiofrequency lesion making. Appl Neurophysiol. 1983;46(1-4):160-6.

61. Farahani K, Mischel PS, Black KL, De Salles AA, Anzai Y, Lufkin RB. Hyperacute thermal lesions: MR imaging evaluation of development in the brain. Radiology. 1995;196(2):517-20.

62. Dupuy DE, Zagoria RJ, Akerley W, Mayo-Smith WW, Kavanagh PV, Safran H. Percutaneous radiofrequency ablation of malignancies in the lung. AJR Am J Roentgenol. 2000;174(1):57-9.

63. Goldberg SN, Gazelle GS, Compton CC, McLoud TC. Radiofrequency tissue ablation in the rabbit lung: efficacy and complications. Acad Radiol. 1995;2(9):776-84.

64. Izzo F, Albino V, Palaia R, Piccirillo M, Tatangelo F, Granata V, et al. Hepatocellular carcinoma: preclinical data on a dual-lumen catheter kit for fibrin sealant infusion following loco-regional treatments. Infect Agent Cancer. 2014:9(1):39.

65. Catalano O, Izzo F, Vallone P, Sandomenico F, Albino V, Nunziata A, et al. Integrating contrast-enhanced sonography in the follow-up algorithm of hepatocellular carcinoma treated with radiofrequency ablation: single cancer center experience. Acta Radiol. 2015;56(2):133-42.

66. Izzo F, Barnett Jr CC, Curley SA. Radiofrequency ablation of primary and metastatic malignant liver tumors. Adv Surg. 2001;35:225-50.

67. Curley SA, Izzo F. Radiofrequency ablation of primary and metastatic liver tumors. Surg Technol Int. 2002;10:99-106.

68. Nouso K, Oonishi A, Wakuta A, Kariyama K. Modified radiofrequency ablation for the treatment of hepatocellular carcinoma. Hepatol Res. 2016 [Epub ahead of print].

69. McGahan JP, Brock JM, Tesluk H, Gu WZ, Schneider P, Browning PD. Hepatic ablation with use of radio-frequency electrocautery in the animal model. J Vasc Interv Radiol. 1992;3(2):291-7.

70. Curley SA. Radiofrequency ablation of malignant liver tumors. Oncologist. 2001:6(1):14-23.

71. Rossi S, Garbagnati F, Lencioni R, Allgaier HP, Marchiano A, Fornari F, et al. Percutaneous radio-frequency thermal ablation of nonresectable hepatocellular carcinoma after occlusion of tumor blood supply. Radiology. 2000:217(1):119-26.

72. Seki T, Tamai T, Ikeda K, Imamura M, Nishimura A, Yamashiki N, et al. Rapid progression of hepatocellular carcinoma after transcatheter arterial chemoembolization and percutaneous radiofrequency ablation in the primary tumour region. Eur J Gastroenterol Hepatol. 2001;13(3):291-4.

73. Ruzzenente A, Manzoni GD, Molfetta M, Pachera S, Genco B, Donataccio M, et al. Rapid progression of hepatocellular carcinoma after Radiofrequency Ablation. World J Gastroenterol. 2004;10(8):1137-40.

74. Kasugai H, Osaki Y, Oka H, Kudo M, Seki T, Osaka Liver Cancer Study G. Severe complications of radiofrequency ablation therapy for hepatocellular carcinoma: an analysis of 3,891 ablations in 2,614 patients. Oncology. 2007; 72 Suppl 1:72-5.

75. Obara K, Matsumoto N, Okamoto M, Kobayashi M, Ikeda H, Takahashi H, et al. Insufficient radiofrequency ablation therapy may induce further malignant transformation of hepatocellular carcinoma. Hepatol Int. 2008;2(1):116-23.

76. Stroescu C, Dragnea A, Ivanov B, Pechianu C, Herlea V, Sgarbura O, et al. Expression of p53, BCl-2, VEGF, Ki67 and PCNA and prognostic significance in hepatocellular carcinoma. J Gastrointestin Liver Dis. 2008;17(4):411-7.

77. Ballardini G, Groff P, Zoli M, Bianchi G, Giostra F, Francesconi R, et al. Increased risk of hepatocellular carcinoma development in patients with cirrhosis and with high hepatocellular proliferation. J Hepatol. 1994;20(2):218-22.

78. Yang P, Yuan W, He J, Wang J, Yu L, Jin X, et al. Overexpression of EphA2, MMP-9, and MVD-CD34 in hepatocellular carcinoma: Implications for tumor progression and prognosis. Hepatol Res. 2009;39(12):1169-77. 